\title{
Factors associated with development of early and late pulmonary hypertension in preterm infants with bronchopulmonary dysplasia
}

\author{
Sudip Sheth ${ }^{1,2} \cdot$ Lisa Goto $^{2} \cdot$ Vineet Bhandari $^{1,2} \cdot$ Boban Abraham $^{2,3} \cdot$ Anja Mowes $^{1,2}$ \\ Received: 26 June 2019 / Revised: 6 October 2019 / Accepted: 28 October 2019 / Published online: 13 November 2019 \\ (c) The Author(s), under exclusive licence to Springer Nature America, Inc. 2019
}

\begin{abstract}
Objective To investigate factors associated with development of early and late pulmonary hypertension (E/LPH) in preterm infants with bronchopulmonary dysplasia (BPD).

Study design A retrospective case-control observational study of preterm infants with BPD admitted to a level IV referral neonatal intensive care unit over 5 years. We compared pre- and postnatal characteristics between infants with or without BPD-associated EPH and LPH.

Results Fifty-nine out of 220 infants (26.8\%) had LPH, while 85 out of 193 neonates (44\%) had EPH. On multiple logistic regression, novel factors associated with development of BPD-LPH included presence of maternal diabetes, EPH, tracheostomy, tracheitis, intraventricular hemorrhage (IVH, grade $\geq 3$ ) and systemic steroid use. For EPH, these were maternal diabetes, IVH grade $\geq 3$, high frequency ventilator use, and absence of maternal antibiotics use.

Conclusion We identified novel factors and confirmed previously established factors with development of LPH and EPH, which can help develop a screening strategy in BPD patients.
\end{abstract}

\section{Introduction}

Bronchopulmonary dysplasia (BPD) is the most common chronic lung disease of infancy in the United States with an incidence of over $30 \%$ in extremely preterm infants, resulting in 10,000-15,000 new cases annually in the United States [1]. Prenatal steroids, gentle ventilation techniques, as well as exogenous surfactant have increased survival rates in preterm infants and decreased the severity of lung injury [2]. Over the last two decades, while survival rates of extremely low birth weight (ELBW) infants has steadily improved, the number of patients with BPD has remained the same or even

Supplementary information The online version of this article (https:// doi.org/10.1038/s41372-019-0549-9) contains supplementary material, which is available to authorized users.

Anja Mowes

akm79@drexel.edu

1 Department of Neonatal-Perinatal Medicine, St. Christopher's Hospital for Children, Philadelphia, PA, USA

2 Drexel University College of Medicine, Philadelphia, PA, USA

3 Department of Pediatric Cardiology, St. Christopher's Hospital for Children, Philadelphia, PA, USA increased $[3,4]$. BPD is associated with increased mortality, poor neurodevelopmental outcome, and long-term respiratory complications in survivors [4-6].

Among the cardiovascular sequelae, pulmonary hypertension $(\mathrm{PH})$ contributes significantly to the high morbidity and mortality in BPD patients. Vascular remodeling, reduced alveolar-capillary surface area, altered distribution of vessels, and abnormal vascular tone and reactivity result in an increase in pulmonary vascular resistance (PVR) [7]. Increased PVR leads to increased pulmonary arterial pressure and subsequently right ventricular (RV) hypertrophy and RV failure. There have been multiple retrospective and prospective studies which have recognized various risk factors for the development of PH in infants with BPD such as LBW, small for gestational age (SGA), duration of mechanical ventilation, use of high frequency ventilation, longer duration of antibiotics, surgical closure of patent ductus arteriosus and severe BPD [8-12]. However some of these studies used a limited number of perinatal factors to seek association with the development of $\mathrm{PH}$. There have been limited studies to find the factors associated with Early $\mathrm{PH}(\mathrm{EPH})$ and also the relationship of EPH with Late PH (LPH) and BPD [9, 13-15]. We conducted a retrospective case-control observational study on a fairly large sample size to investigate the association of multiple perinatal factors using standardized 
definitions for development of EPH and LPH using defined echocardiographic criteria in preterm infants with BPD. We used a comprehensive list of pre- and postnatal variables with the goal of a detailed analysis of all potential risk factors contributing to E/LPH. In addition, we investigated the relationship between EPH and LPH, with the aim of an earlier detection of BPD-LPH for a potential future utility of an improved therapeutic approach to identify and manage BPD-LPH to decrease morbidity/mortality in these infants.

\section{Material and methods}

\section{Study design}

This study was approved by the Institutional Review Board at St. Christopher's Hospital for Children in Philadelphia, PA and Drexel University College of Medicine, Philadelphia PA. The study population was a retrospective, observational cohort of patients at St. Christopher's Hospital for Children (SCHC) from January 2012 to December 2016. SCHC is an academic, urban hospital in Philadelphia, PA, USA with a 39bed level IV neonatal intensive care unit (NICU), which has around 300 admissions a year referred from adjacent level I, II and III NICUs as well as from emergency rooms. Infants $<32$ weeks gestational age (GA) at birth, and with a birth weight (BW) of $<1500 \mathrm{~g}$ were identified using electronic medical records. Patients were excluded if they died $<28$ day of life (DOL), medical records were missing or if they had multiple anomalies/aneuploidy, congenital heart disease (CHD, other than atrial septal defect (ASD), ventricular septal defect (VSD), or PDA), or congenital lung disease.

\section{Definitions}

\section{Bronchopulmonary dysplasia}

The BPD consensus definition for infants with GA $<32$ weeks was used to categorize and classify our patient population [16], i.e., treatment with oxygen for at least 28 days with categorization into the following three subgroups at 36 weeks' postmenstrual age (PMA): (1) mild (breathing room air); (2) moderate (need for a $<0.3$ fraction of inspired oxygen $\left(\mathrm{FiO}_{2}\right)$ ), and (3) severe (need for $\geq 0.3 \mathrm{FiO}_{2}$ and/or positive pressure support). Infants with BPD who died of respiratory causes before the assessment date (i.e., after $28 \mathrm{DOL}$ and before 36 weeks PMA) were included in the analysis and considered to have "severe disease" [17, 18].

\section{Pulmonary hypertension (PH)}

The primary outcome was Late $\mathrm{PH}(\mathrm{LPH})$, defined as $\mathrm{PH}$ diagnosed $\geq 28$ DOL, while we divided Early PH (EPH) in three categories. (1) EPH I: PH diagnosed $\leq 7$ DOL, (2) EPH II: PH diagnosed $\leq 14$ DOL and (3) EPH III: PH diagnosed $<28$ DOL. PH was defined based on the following echocardiogram criteria [10, 19]: (1) RV systolic pressure (SP) $>40 \mathrm{mmHg}$; (2) RVSP/systemic systolic blood pressure ratio $>0.5$; (3) Any VSD or PDA with bidirectional or rightto-left shunting; (4) If no tricuspid regurgitation (TR) jet or shunt present then two out of following three criteria: (a) Any degree of interventricular septal flattening; (b) RV dilatation; (c) RV hypertrophy. As per our NICU protocol, all the echocardiograms in NICU are transthoracic complete echocardiograms (CEs) with color doppler unless specified by a neonatologist or a cardiologist to be a limited echocardiogram to look for specific pathology. As part of our NICU protocol, which was implemented in July 2015, CEs to screen for PH are performed at corrected 36 weeks PMA and interpreted by pediatric cardiologists for the patients who are diagnosed with any stage of BPD.

\section{Echocardiographic variables}

Interpretation of all the CEs performed on the infants were reviewed by the study team. Directionality of the shunt through an ASD, patent foramen ovale (PFO), VSD, or PDA was entered as (1) left-to-right (2) right-to-left or (3) bidirectional. Right ventricular dilatation, hypertrophy, septal flattening, and TR jet were defined as either present or absent. Reported RV pressure and systemic pressures were recorded as numerical. ASDs were categorized as (1) none (2) PFO, (3) PFO vs. ASD or (4) ASD. PDA was defined as (1) none (2) small (3) moderate (4) large as defined by Ramos et al. [20]. Hemodynamically significant PDA was defined as per Zonnenberg et al. [21].

\section{Clinical variables}

Data abstracted from the patient's chart included maternal history, prenatal characteristics, intrapartum history, postpartum history, and postnatal NICU course along with multiple complications as shown in Tables 1 and 2 . Antenatal diagnoses such as gestational diabetes, intrauterine growth restriction (IUGR), preeclampsia, preterm premature rupture of the membranes (PPROM), and chorioamnionitis were defined as per the American College of Obstetricians and Gynecologists (ACOG) guidelines [22-26]. Maternal diabetes included preexisting as well as gestational diabetes. Maternal antibiotics included any antibiotics given to the mother in the antenatal period except if given for presurgical prophylaxis. Tracheitis was defined as following: (1) absence of clinical or radiographic evidence of pneumonia, AND (2) a positive culture obtained by deep tracheal aspirate or bronchoscopy, AND (3) $\geq 2$ of the following signs or symptoms with no other 
Table 1 General characteristics

\begin{tabular}{ll}
\hline Characteristics & Total sample $(N=220)$ \\
\cline { 2 - 2 } & Number $(\%)$ Median (IQR) \\
\hline
\end{tabular}

Prenatal characteristics

Maternal age

Antenatal steroid ( $\geq 1$ dose)

IUGR

Preeclampsia

Maternal diabetes

Oligohydramnios

Tobacco/alcohol use

Substance use

Prolonged ROM (>18 h)

PPROM

Chorioamnionitis

C-section

Postnatal characteristics

GA at birth (weeks)

Birth weight (grams)

Sex

Male

Female

Race

White

African American

Hispanic

Asian

Other

Small for gestational age

Multiple births

APGAR

$1 \mathrm{~min}$
$5 \mathrm{~min}$
$10 \mathrm{~min}$

Morbidity and mortality

Death

Tracheostomy

Bacteremia

Tracheitis

Pneumothorax

IVH (Grade 3-4)

NEC (Any stage)

Gastrostomy-tube

Hemodynamically

significant PDA

PDA- Surgical closure

ROP- laser or avastin use

Bronchopulmonary dysplasia

Mild
17 (7.7)

$25+6(22-31+0)$

750 (330-1460)

129 (58.6)

$91(41.4)$

27 (12.3)

$96(43.6)$

41 (18.6)

8 (3.6)

$48(21.8)$

28 (12.7)

$56(25.5)$

$4(0-9)$

$6.5(0-9)$

$7(1-10)$

$27(12.3)$

$88(40)$

$21(9.5)$

39 (17.7)

$64(29.1)$

$66(30)$

$109(49.5)$

$42(19.1)$

79 (35.9)

$28(12.7)$
77 (35.0)
Table 1 (continued)

\begin{tabular}{ll}
\hline Characteristics & Total sample $(N=220)$ \\
\cline { 2 - 2 } & Number $(\%)$ Median (IQR) \\
\hline Moderate & $21(9.5)$ \\
Severe & $171(77.7)$ \\
Pulmonary hypertension & \\
EPH I ( $\leq 7$ DOL) & $62(43)$ \\
EPH II ( $\leq 14$ DOL) & $72(40.9)$ \\
EPH III (<28 DOL) & $85(44)$ \\
LPH (>28 DOL) & $59(26.8)$ \\
\hline
\end{tabular}

$I Q R$ interquartile range, IUGR intrauterine growth retardation, $P P R O M$ preterm premature rupture of the membranes, $I V H$ intraventricular hemorrhage, $P V L$ periventricular leukomalacia, $N E C$ necrotizing enterocolitis, $R O P$ retinopathy of prematurity, $P D A$ patent ductus arteriosus, $C$-section cesarean section, $D O L$ day of life, $E P H$ early pulmonary hypertension, $L P H$ late pulmonary hypertension

recognized cause: temperature $>38$ or $<36{ }^{\circ} \mathrm{C}$, new or increased sputum production, rhonchi, or wheezing, respiratory distress, apnea, or bradycardia $(<100 \mathrm{bpm})$ $[27,28]$. In our NICU, it is usual clinical practice to collect tracheal culture in the presence of any of above symptoms in the absence of pneumonia findings on chest $\mathrm{x}$-ray. It is a routine clinical practice in our NICU to administer tapering doses of dexamethasone for 10 days as per the DART protocol for BPD patients requiring prolonged invasive mechanical ventilation [29]. Bacteremia was defined as any positive blood culture during the NICU stay for the patient. Intraventricular hemorrhage (IVH) was classified as per Papile et al., while periventricular leukomalacia (PVL) was defined as described by Banker et al. [30, 31]. IVH intervention included ventricular reservoir and/or ventriculoperitoneal shunt placements. Modified Bell's criteria were used to classify necrotizing enterocolitis (NEC), while International Classification for Retinopathy of Prematurity was used to diagnose and classify retinopathy of prematurity (ROP) [32, 33].

\section{Descriptive statistics}

All data were retrospectively collected using the electronic medical records. Chi-square test was used to assess the association between categorical variables unless the cell frequency was $\leq 5$, in which case the Fisher's exact test was used. Distribution of continuous variables was assessed using the Shapiro-Wilk test. Normally distributed continuous variables were analyzed using independent sample $t$-test, while Mann-Whitney U test was used for non-normal distributions. To determine the effect of all the prenatal and postnatal variables on the outcome of LPH and EPH, binomial logistic regression was used to arrive at odds ratios (OR), and 95\% confidence intervals (CI). Adjusted OR 
Table 2 Factors associated with development of LPH

\begin{tabular}{|c|c|c|c|c|c|c|}
\hline Variables & $\begin{array}{l}\text { LPH }(N=59) \\
n(\%)\end{array}$ & $\begin{array}{l}\text { No LPH }(N=161) \\
n(\%)\end{array}$ & $P$ value & $\begin{array}{l}\text { Unadjusted OR } \\
(95 \% \mathrm{CI})\end{array}$ & $P$ value & $\begin{array}{l}\text { Adjusted OR } \\
(95 \% \mathrm{CI})\end{array}$ \\
\hline \multicolumn{7}{|l|}{ Maternal factors } \\
\hline Maternal age, mean (SD) & $26.2(5.0)$ & $27.5(6.5)$ & 0.179 & $0.966(0.918-1.016)$ & 0.100 & $0.956(0.906-1.009)$ \\
\hline Gravida, mean (SD) & $3(1.8)$ & $3.34(2.2)$ & 0.293 & $0.922(0.793-1.073)$ & 0.407 & $0.935(0.798-1.096)$ \\
\hline Para, mean (SD) & $2.2(1.3)$ & $2.2(1.3)$ & 0.625 & $0.943(0.745-1.1193)$ & 0.969 & $1.005(0.782-1.291)$ \\
\hline $\begin{array}{l}\text { Antenatal steroid } \\
(\geq 1 \text { dose })\end{array}$ & $45(76.3)$ & $107(66.5)$ & 0.165 & $1.622(0.819-3.212)$ & 0.411 & $1.346(0.662-2.736)$ \\
\hline IUGR & $9(15.3)$ & $14(8.7)$ & 0.164 & $1.890(0.771-4.634)$ & 0.693 & $1.215(0.462-3.195)$ \\
\hline Preeclampsia & $15(25.4)$ & $34(21.1)$ & 0.497 & $1.273(0.634-2.558)$ & 0.668 & $0.847(0.397-1.808)$ \\
\hline Magnesium sulfate use & $35(59.3)$ & $72(44.7)$ & 0.056 & $1.803(0.984-3.302)$ & 0.150 & $1.584(0.846-2.966)$ \\
\hline Maternal diabetes & 7 (11.9) & $6(3.7)$ & $0.031 *$ & 3.478 (1.118-10.817) & $0.047 *$ & $3.412(1.016-11.456)$ \\
\hline Oligohydroamnios & $4(6.8)$ & $11(6.8)$ & 0.989 & $0.992(0.303-3.245)$ & 0.670 & $0.763(0.220-2.651)$ \\
\hline Tobacco/Alcohol use & $10(16.9)$ & $15(9.3)$ & 0.119 & $1.986(0.838-4.709)$ & 0.055 & $2.441(0.980-6.081)$ \\
\hline Substance use & $9(15.3)$ & $29(18)$ & 0.632 & $0.819(0.362-1.852)$ & 0.551 & $0.775(0.335-1.793)$ \\
\hline Prolonged ROM ( $>18$ h) & 7 (11.9) & $29(18)$ & 0.278 & $0.613(0.253-1.485)$ & 0.310 & $0.626(0.253-1.547)$ \\
\hline PPROM & $15(25.4)$ & $43(26.7)$ & 0.848 & $0.936(0.473-1.851)$ & 0.985 & $0.993(0.491-2.007)$ \\
\hline Chorioamnionitis & $6(10.2)$ & $20(12.4)$ & 0.647 & $0.798(0.304-2.096)$ & 0.837 & $0.900(0.330-2.454)$ \\
\hline Maternal antibiotics & $21(35.6)$ & $62(38.5)$ & 0.77 & $0.914(0.499-1.673)$ & 0.784 & $0.914(0.480-1.739)$ \\
\hline C-section & $39(66.1)$ & $112(69.6)$ & 0.486 & $0.802(0.432-1.491)$ & 0.391 & $0.748(0.385-1.453)$ \\
\hline \multicolumn{7}{|l|}{ Newborn history } \\
\hline GA at birth, mean (SD) & $25+4$ (11 days) & $26+0$ (12 days) & 0.105 & $0.863(0.722-1.031)$ & 0.507 & $1.083(0.856-1.371)$ \\
\hline BW, grams, mean (SD) & $690(224)$ & 807 (206) & $0.001 *$ & $0.997(0.996-0.999)$ & $0.003 *$ & 0.997 (0.996-0.999) \\
\hline Sex (female) & $32(54.2)$ & 59 (36.6) & 0.020 & 2.049 (1.120-3.749) & 0.148 & $1.598(0.846-3.018)$ \\
\hline SGA & $16(27.1)$ & $12(7.5)$ & $0.000 *$ & $4.620(2.031-10.509)$ & $0.042 *$ & 2.703 (1.036-7.057) \\
\hline Multiple births & $15(25.4)$ & $41(25.5)$ & 0.995 & $0.998(0.503-1.979)$ & 0.581 & $1.224(0.597-2.507)$ \\
\hline \multicolumn{7}{|c|}{ Delivery room $(D R)$ resuscitation } \\
\hline $\begin{array}{l}\text { Meconium stained } \\
\text { amniotic fluid }\end{array}$ & $2(3.4)$ & $4(2.5)$ & 0.926 & $1.072(0.249-4.625)$ & 0.643 & $1.414(0.326-6.138)$ \\
\hline 1 min, mean $(\mathrm{SD})$ & $3.5(2.1)$ & $3.7(2.4)$ & 0.139 & $0.904(0.792-1.033)$ & 0.297 & $0.928(0.806-1.068)$ \\
\hline 5 min, mean $(\mathrm{SD})$ & $5.6(2.3)$ & $6.5(2.1)$ & 0.017 & $0.849(0.742-0.971)$ & 0.087 & $0.884(0.768-1.018)$ \\
\hline CPAP in DR & $52(89.7)$ & $150(93.2)$ & 0.395 & $0.636(0.224-1.804)$ & 0.276 & $0.545(0.183-1.624)$ \\
\hline PPV in DR & $54(91.5)$ & $134(83.2)$ & 0.129 & $2.176(0.796-5.946)$ & 0.413 & $1.548(0.543-4.413)$ \\
\hline Intubation in DR & $52(88.1)$ & $123(76.4)$ & 0.061 & $2.295(0.963-5.472)$ & 0.294 & $1.637(0.653-4.105)$ \\
\hline Surfactant in DR & $29(49.2)$ & $81(50.6)$ & 0.847 & $0.943(0.519-1.713)$ & 0.272 & $0.695(0.364-1.329)$ \\
\hline \multicolumn{7}{|l|}{ NICU course } \\
\hline Surfactant doses ( $\geq 1$ dose $)$ & $53(89.8)$ & $134(83.2)$ & 0.165 & $1.622(0.819-3.212)$ & 0.411 & $1.346(0.662-2.736)$ \\
\hline HFOV use & $51(86.4)$ & $69(43.4)$ & $0.000 *$ & $8.315(3.704-18.666)$ & $0.000 *$ & $7.072(3.053-16.381)$ \\
\hline PPV use (>30 days) & $31(52.5)$ & $99(61.5)$ & 0.233 & $0.693(0.380-1.265)$ & 0.185 & $0.655(0.350-1.225)$ \\
\hline NC use (>30 days) & $9(15.3)$ & $28(17.4)$ & 0.708 & $0.855(0.377-1.938)$ & 0.929 & $1.039(0.452-2.386)$ \\
\hline $\begin{array}{l}\text { Mechanical Ventilation } \\
\text { ( }>30 \text { days) }\end{array}$ & 47 (79.7) & $84(52.2)$ & $0.000^{*}$ & $3.590(1.773-7.268)$ & $0.008 *$ & $2.781(1.302-5.944)$ \\
\hline Tracheostomy & $17(28.8)$ & $10(6.2)$ & $0.000 *$ & $6.112(2.605-14.338)$ & $0.000 *$ & $5.141(2.105-12.554)$ \\
\hline Caffeine use & $56(94.9)$ & $159(98.8)$ & 0.118 & $0.235(0.038-1.442)$ & 0.106 & $0.208(0.031-1.395)$ \\
\hline Bacteremia & $23(39)$ & $54(33.5)$ & 0.454 & $1.266(0.683-2.346)$ & 0.812 & $1.082(0.566-2.069)$ \\
\hline Antibiotic days ( $>30$ days) & $34(57.6)$ & $55(34.2)$ & $0.002 *$ & $2.621(1.423-4.826)$ & $0.019 *$ & 2.177 (1.138-4.166) \\
\hline Tracheitis & $33(55.9)$ & $55(34.2)$ & $0.004 *$ & $2.446(1.331-4.495)$ & $0.045^{*}$ & $1.934(1.016-3.683)$ \\
\hline Pneumonia & $7(12.1)$ & $14(8.7)$ & 0.456 & $1.441(0.551-3.770)$ & 0.607 & $1.300(0.478-3.540)$ \\
\hline Pneumothorax & $10(16.9)$ & $11(6.8)$ & 0.028 & $2.783(1.115-6.949)$ & 0.052 & $2.614(0.993-6.882)$ \\
\hline
\end{tabular}


Table 2 (continued)

\begin{tabular}{|c|c|c|c|c|c|c|}
\hline Variables & $\begin{array}{l}\mathrm{LPH}(N=59) \\
n(\%)\end{array}$ & $\begin{array}{l}\text { No LPH }(N=161) \\
n(\%)\end{array}$ & $P$ value & $\begin{array}{l}\text { Unadjusted OR } \\
(95 \% \mathrm{CI})\end{array}$ & $P$ value & $\begin{array}{l}\text { Adjusted OR } \\
(95 \% \mathrm{CI})\end{array}$ \\
\hline IVH $\geq$ Grade III & $17(28.8)$ & $22(13.7)$ & $0.011 *$ & $2.557(1.244-5.259)$ & $0.012 *$ & $2.616(1.235-5.541)$ \\
\hline IVH intervention & $4(6.8)$ & $9(5.6)$ & 0.741 & $1.228(0.364-4.150)$ & 0.597 & $1.410(0.395-5.039)$ \\
\hline PVL & $9(15.3)$ & $11(6.8)$ & 0.060 & $2.455(0.961-6.267)$ & 0.056 & $2.578(0.976-6.811)$ \\
\hline NEC & $19(32.2)$ & $45(28.0)$ & 0.539 & $1.224(0.642-2.335)$ & 0.915 & $0.964(0.488-1.903)$ \\
\hline Intestinal perforation & $13(22)$ & $25(15.5)$ & 0.260 & $1.537(0.727-3.251)$ & 0.615 & $1.226(0.555-2.708)$ \\
\hline ROP (any stage) & $43(72.9)$ & $97(60.2)$ & 0.087 & $1.773(0.921-3.414)$ & 0.520 & $1.264(0.620-2.576)$ \\
\hline Laser and/or Avastin & $26(44.1)$ & $53(33.5)$ & 0.148 & $1.552(0.856-2.811)$ & 0.790 & $1.096(0.558-2.151)$ \\
\hline Gastrostomy-tube & $27(45.8)$ & $39(24.2)$ & $0.002 *$ & $2.639(1.411-4.938)$ & $0.013^{*}$ & $2.272(1.187-4.348)$ \\
\hline $\begin{array}{l}\text { Hemodynamically } \\
\text { significant PDA }\end{array}$ & $31(52.5)$ & $78(48.4)$ & 0.591 & $1.178(0.648-2.141)$ & 0.787 & $0.917(0.487-1.724)$ \\
\hline EPH I ( $\leq 7$ days $)(n=144)$ & $20(51.3)$ & $42(40.0)$ & 0.226 & $1.579(0.754-3.307)$ & 0.097 & $1.941(0.886-4.253)$ \\
\hline $\begin{array}{l}\text { EPH II ( } \leq 14 \text { days }) \\
(n=176)\end{array}$ & $24(52.2)$ & $48(36.9)$ & 0.072 & $1.864(0.945-3.676)$ & $0.035 *$ & $2.175(1.056-4.477)$ \\
\hline $\begin{array}{l}\text { EPH III* (<28 days }) \\
(n=193)\end{array}$ & $31(63.3)$ & $54(37.5)$ & $0.002 *$ & $2.870(1.456-5.619)$ & $0.002 *$ & $3.178(1.554-6.500)$ \\
\hline PDA surgical closure (any) & $17(28.8)$ & $25(15.5)$ & 0.029 & $2.202(1.086-4.464)$ & 0.087 & $1.897(0.912-3.946)$ \\
\hline BPD (severe) & $56(94.9)$ & $115(71.4)$ & $0.001 *$ & $7.467(2.225-25.059)$ & $0.005 *$ & $5.763(1.684-19.717)$ \\
\hline $\begin{array}{l}\text { Steroid use for BPD } \\
\text { ( }>7 \text { days) }\end{array}$ & $26(44.1)$ & $22(13.7)$ & $0.000 *$ & $4.978(2.515-9.855)$ & $0.000 *$ & $4.230(2.085-8.583)$ \\
\hline Death & $10(16.9)$ & $7(4.3)$ & 0.004 & $4.490(1.622-12.426)$ & 0.067 & $2.729(0.931-7.999)$ \\
\hline
\end{tabular}

$B P D$ bronchopulmonary dysplasia, $L P H$ late pulmonary hypertension, $O R$ odds ratio, $C I$ confidence interval, $I U G R$ intrauterine growth retardation, $P P R O M$ preterm premature rupture of the membranes, $G A$ gestational age, $B W$ birth weight, $S D$ standard deviation, $S G A$ small for gestational age, $C P A P$ continuous positive airway pressure, $P P V$ positive pressure ventilation, $H F O V$ high frequency oscillator ventilator, $N C$ nasal cannula, $I V H$ intraventricular hemorrhage, $P V L$ periventricular leukomalacia, $N E C$ necrotizing enterocolitis, $R O P$ retinopathy of prematurity, $P D A$ patent ductus arteriosus, $E P H$ early pulmonary hypertension, $C$-section cesarean section

Bold values indicate statistical significance $p \leq 0.05$

were determined by multiple logistic regression, to control for possible confounding effects of other variables. In the multivariate model, LPH (yes or no) and EPH (yes or no) were considered as the dependent variables separately, and all the prenatal and postnatal variables were analyzed as independent variables, which were adjusted for BW and sex as covariates. We also replaced BW with GA, with no major impact in our results. All data were analyzed with SPSS 24.0 for Windows (SPSS Inc, Chicago, IL). All statistical tests were two-tailed, and $P$ values $\leq 0.05$ were considered statistically significant. The Hosmer-Lemeshow test was conducted to determine the model's goodness of fit.

\section{Results}

\section{Patient selection}

As per Figure 1, over a 5-year-period after using inclusion and exclusion criteria, we found 258 patients with BPD, who fit the NIH consensus definition. We had to exclude 38 patients as none of them received any $\mathrm{CE} \geq 28 \mathrm{DOL}$. The median GA at birth was $25+6$ weeks (range, $22-31+0$ weeks), and the median BW was $750 \mathrm{~g}$ (range, 330-1460 g). Out of 220 patients, 144, 176, and 193 patients had received at least one $\mathrm{CE} \leq 7 \mathrm{DOL}, \leq 14 \mathrm{DOL}$, and $<28 \mathrm{DOL}$, respectively. So, while analyzing data with EPH I, II, and III, we considered only those patients who received at least one $\mathrm{CE}$ in their respective time period. The pre- and postnatal characteristics of the infants studied are presented in Table 1.

\section{Pulmonary hypertension}

As the PH screening protocol was implemented in middle of the study period, not all patients included in the study received a screening echocardiogram at 36 weeks of GA. Instead, all 220 patients had at least one $\mathrm{CE} \geq 28$ DOL. CEs done before 28 DOL were performed for various indications including evaluating for PH, PDA, heart function, as well as to rule out CHD. Being a referral center, patients were admitted at different ages; hence, the total number of CEs received by each patient was different. Median age to diagnose LPH was $37+$ 4 adjusted weeks of gestation (range, $26+4-73+6$ ) and 79 DOL (range, 29-328 DOL). Out of all the LPH cases, 45.8\%, 
Fig. 1 Flowchart of study patient selection

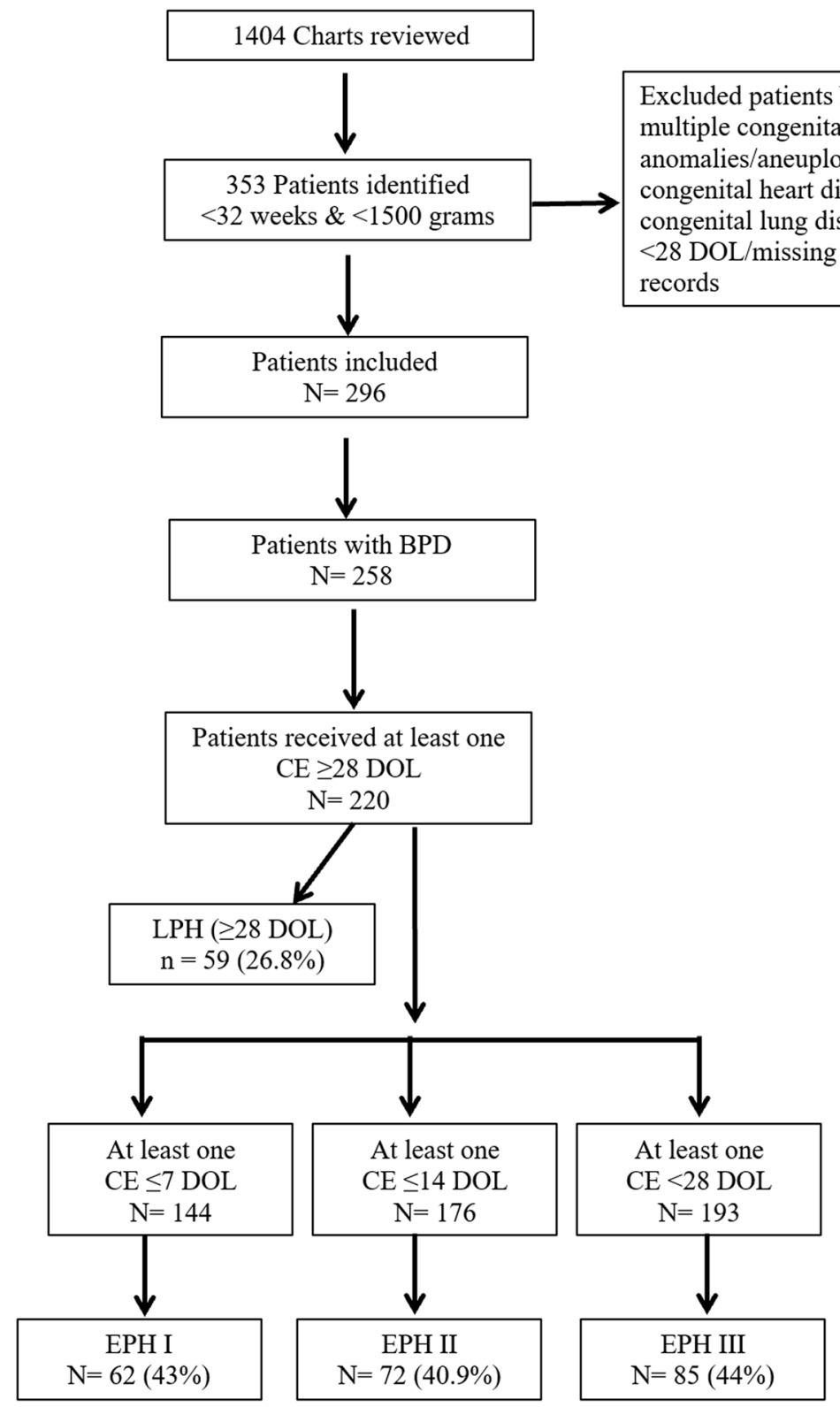

$15.3 \%, 15.3 \%$, and $23.7 \%$ were diagnosed using criteria 1,2 , 3 and 4 respectively, while out of all EPH cases $27.1 \%$, $28.2 \%, 25.9 \%$, and $18.8 \%$ were diagnosed using criteria 1,2 , 3 , and 4 respectively. Figure 2 shows the distribution of LPH with the degree of BPD severity.

\section{Factors associated with LPH and EPH II in patients with BPD}

Comparison of characteristics between those with or without LPH has been shown in Table 2. Excluding infants who died (i.e., after 28 DOL and before 36 weeks PMA; $n=6$ ) did not impact our results. The novel factors associated with development in LPH in our study were maternal diabetes (OR,
95\% CI; 3.412, 1.016-11.456), EPH II and III $(p<0.05)$, tracheostomy $(5.141,2.105-12.554)$, tracheitis (1.934, 1.016-3.683), IVH grade $\geq 3 \quad(2.616,1.235-5.541)$, Gastrostomy-tube (G-tube) placement (2.272, 1.187-4.348), and systemic steroid use for BPD (4.230, 2.085-8.583. Table 3 shows comparison of characteristics between those with or without EPH II. Only 176 out of 220 patients were included as they received at least one CE $\leq 14$ DOL.

\section{Association of PDA surgical closure with LPH and BPD}

Supplemental Table 1 shows the relationship of different PDA surgical closure timing with development of LPH; we 


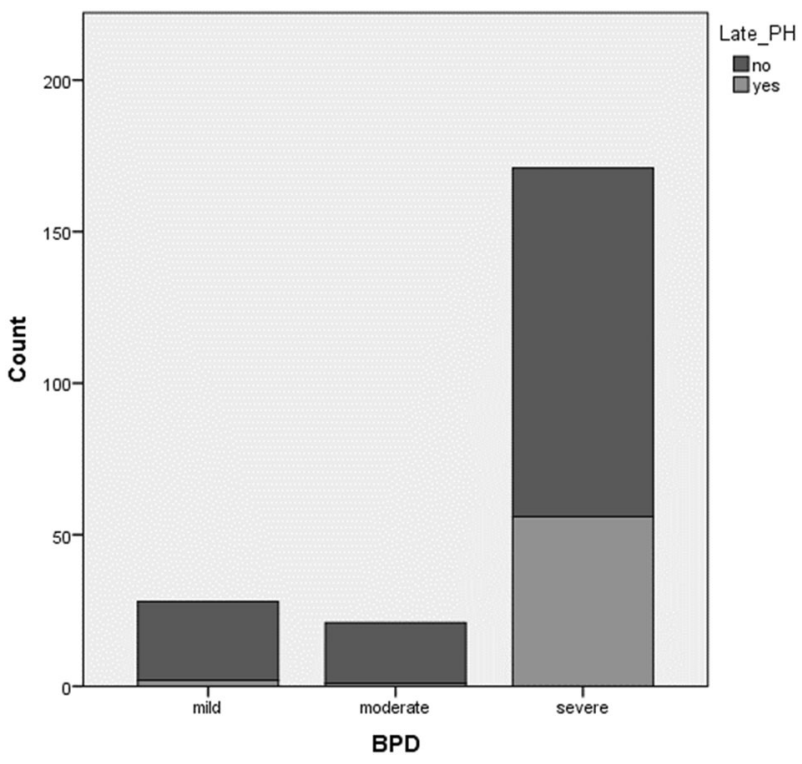

Fig. 2 The development of LPH with the degree of BPD severity

did not find any association of early vs. late surgical closure of PDA with development of LPH in later life.

\section{Discussion}

This study was carried out to comprehensively evaluate multiple pre- and postnatal factors that could impact the development of LPH and EPH in infants with BPD. We confirmed several well-known factors [34], and determined several novel factors associated with the development of LPH and EPH in patients with BPD.

Different studies have defined LPH as PH diagnosed after 2, 4, 36 weeks PMA or on final echocardiograms before discharge [9, 13-15, 35]. To qualify for the BPD definition, an infant should require treatment with $>0.21$ $\mathrm{FiO}_{2}$ for at least 28 days and then classified at 36 weeks PMA [16]. On that basis, we used the cutoff at 28 DOL to define LPH and EPH. There have been a few studies, which have defined $\mathrm{EPH}$ as $\mathrm{PH}$ diagnosed within first week, 2 weeks or 4 weeks of life [8,9,13-15]. It is possible that different pathways could be at play contributing to the pathogenesis of $\mathrm{PH}$ diagnosed during these time periods; hence, we divided EPH in three different categories to see if any of them could predict the development of LPH in BPD patients.

As previously shown, we confirmed several factors associated with development of LPH, including LBW, SGA, high frequency oscillatory ventilation (HFOV), longer use of mechanical ventilation, longer use of antibiotics, and severe BPD [8, 10-12, 36]. However, in contrast to previously described associations, we did not find a significant association with development of LPH with the use of antenatal steroids, IUGR, oligohydramnios, PPROM, modes of resuscitation used in delivery room, APGAR scores, surfactant use, surgical closure of PDA, or multiple gestation $[9,10,35,37-39]$. A number of reasons could explain the lack of significant association with the factors noted above; among them, the most likely one is probably the differences in our patient/referral population, compared with other studies. In addition, we did not find any difference in incidence of developing LPH with different timing of PDA surgical closure (Supplemental Table 1).

Of note, maternal diabetes appeared to be an independent risk factor for the development of LPH. Out of 13 diabetic mothers, 6 had type II diabetes and 7 had gestational diabetes. To the best of our knowledge, such a relationship between maternal diabetes and LPH has not been previously reported. Maternal diabetes has been associated with persistent pulmonary hypertension in term newborn infants [40]. Recently, it has been proposed that BPD has its origins during fetal life and antenatal events including maternal placental under-perfusion are determining factors of the development of BPD [41-44]. Diabetes can result in endothelial dysfunction and vascular inflammation [45], which might be associated with maternal under-perfusion and in turn be associated with BPD as well as LPH in these infants. As the screening test for gestational diabetes is done from 24 to 28 weeks of GA unless at high risk for diabetes, we might have missed some of the mothers who potentially would have been diagnosed with gestational diabetes later during pregnancy [22].

There might be a different pathogenesis for $\mathrm{PH}$ diagnosed within 1, 2 or 4 weeks of life, but interestingly $\mathrm{PH}$ diagnosed within 2 and 4 weeks of life (EPH II and III) were significantly associated with development of LPH in preterm infants with BPD in our study.

Surprisingly, when we compared the characteristics from the same dataset to assess the factors associated with EPH II (Table 3), there were a few that overlapped with that of LPH: maternal diabetes, HFOV use and IVH $\geq$ grade 3 and absence of maternal antibiotic use. Most of these factors were consistently associated with EPH I and III. Multiple theories including maternal placental under-perfusion, disruption of normal angiogenesis etc. can be applied to this association. In the clinical setting, early $\mathrm{CE}<28 \mathrm{DOL}$ can be very useful for the early identification of preterm infants at high risk for BPD and LPH.

The presence of tracheitis, IVH grade $\geq 3$, G-tube placement, systemic steroid use for BPD, and tracheostomy were additional novel factors in our study. These conditions might be associated with high risk of developing LPH due to the presence and persistence of inflammation in the airway and lung parenchyma, as well as due to severity of illness. Fourteen $(82 \%)$ out of 17 patients who required tracheostomy were already diagnosed with LPH before 
Table 3 Factors associated with development of EPH II

\begin{tabular}{|c|c|c|c|c|c|c|}
\hline Variable & $\begin{array}{l}\text { EPH II }(N=72) \\
n(\%)\end{array}$ & $\begin{array}{l}\text { No EPH II }(N=104) \\
n(\%)\end{array}$ & $P$ value & $\begin{array}{l}\text { Unadjusted OR } \\
(95 \% \mathrm{CI})\end{array}$ & $P$ value & $\begin{array}{l}\text { Adjusted OR } \\
(95 \% \mathrm{CI})\end{array}$ \\
\hline \multicolumn{7}{|l|}{ Maternal Factors } \\
\hline Maternal age, mean (SD) & $27(6.2)$ & $27.3(5.7)$ & 0.749 & $0.992(0.942-1.044)$ & 0.717 & $0.991(0.941-1.043)$ \\
\hline Gravida, mean (SD) & $3.3(2.4)$ & $3.4(2.0)$ & 0.889 & $0.990(0.861-1.139)$ & 0.769 & $0.979(0.849-1.128)$ \\
\hline Para, mean (SD) & $2.2(1.2)$ & $2.3(1.3)$ & 0.440 & $0.910(0.715-1.157)$ & 0.335 & $0.886(0.694-1.132)$ \\
\hline $\begin{array}{l}\text { Antenatal steroid } \\
(\geq 1 \text { dose })\end{array}$ & $46(63.9)$ & $75(72.1)$ & 0.248 & $0.684(0.359-1.303)$ & 0.295 & $0.705(0.366-1.357)$ \\
\hline IUGR & $10(13.9)$ & $8(7.7)$ & 0.188 & $1.935(0.724-5.173)$ & 0.104 & $2.358(0.839-6.626)$ \\
\hline Preeclampsia & $17(23.6)$ & $22(21.2)$ & 0.700 & $1.152(0.561-2.365)$ & 0.550 & $1.255(0.596-2.642)$ \\
\hline Magnesium sulfate use & $36(50.0)$ & $50(48.1)$ & 0.802 & $1.080(0.592-1.970)$ & 0.714 & $1.121(0.610-2.060)$ \\
\hline Maternal Diabetes & 7 (9.7) & $3(2.9)$ & 0.069 & $3.626(0.905-14.527)$ & $0.044 *$ & $4.251(1.040-17.375)$ \\
\hline Oligohydramnios & $4(5.6)$ & $8(7.7)$ & 0.582 & $0.706(0.204-2.439)$ & 0.726 & $0.799(0.227-2.811)$ \\
\hline Tobacco/Alcohol use & $11(15.3)$ & $12(11.5)$ & 0.471 & $1.383(0.574-3.332)$ & 0.446 & $1.417(0.578-3.471)$ \\
\hline Substance use & $13(18.1)$ & $17(16.3)$ & 0.767 & $1.128(0.510-2.495)$ & 0.751 & $1.138(0.512-2.526)$ \\
\hline Prolonged ROM ( $>18$ h) & $8(11.1)$ & $20(19.2)$ & 0.152 & $0.525(0.217-1.268)$ & 0.160 & $0.530(0.219-1.284)$ \\
\hline PPROM & $18(25.0)$ & $27(26.0)$ & 0.886 & $0.951(0.477-1.896)$ & 0.887 & $0.951(0.475-1.902)$ \\
\hline Chorioamnionitis & $5(6.9)$ & $16(15.4)$ & 0.098 & $0.410(0.143-1.177)$ & 0.105 & $0.415(0.143-1.203)$ \\
\hline Maternal antibiotics & $19(26.4)$ & $45(43.3)$ & $0.023 *$ & $0.470(0.245-0.902)$ & $0.023 *$ & $0.467(0.243-0.900)$ \\
\hline C-section & $51(70.8)$ & $72(69.2)$ & 0.820 & $1.079(0.560-2.082)$ & 0.810 & $1.084(0.559-2.102)$ \\
\hline \multicolumn{7}{|l|}{ Newborn history } \\
\hline GA at birth, mean (SD) & $26+0$ (12 days) & $25+3$ (11 days $)$ & 0.039 & $1.216(1.010-1.464)$ & 0.090 & $1.232(0.968-1.569)$ \\
\hline BW, grams, mean (SD) & $774.1(226)$ & $728.6(185)$ & 0.250 & $1.001(0.999-1.002)$ & 0.214 & $1.001(0.999-1.002)$ \\
\hline Sex (female) & $31(43.1)$ & $43(41.3)$ & 0.821 & $1.073(0.584-1.971)$ & 0.597 & $1.186(0.631-2.230)$ \\
\hline SGA & $9(12.5)$ & $14(13.5)$ & 0.852 & $0.918(0.374-2.252)$ & 0.687 & $1.235(0.442-3.453)$ \\
\hline Multiple births & $15(20.8)$ & $34(32.7)$ & 0.087 & $0.542(0.269-1.092)$ & 0.058 & $0.500(0.244-1.025)$ \\
\hline \multicolumn{7}{|c|}{ Delivery room $(D R)$ resuscitation } \\
\hline $\begin{array}{l}\text { Meconium stained } \\
\text { amniotic fluid }\end{array}$ & $1(1.4)$ & $4(3.8)$ & 0.355 & $0.352(0.039-3.217)$ & 0.331 & $0.332(0.036-3.062)$ \\
\hline 1 min, mean $(\mathrm{SD})$ & $3.9(2.3)$ & $4(2.4)$ & 0.794 & $0.983(0.863-1.119)$ & 0.631 & $0.968(0.849-1.105)$ \\
\hline 5 min, mean $(\mathrm{SD})$ & $6.2(2.2)$ & $6.2(2.3)$ & 0.966 & $0.997(0.872-1.141)$ & 0.817 & $0.984(0.858-1.128)$ \\
\hline CPAP in DR & $64(88.9)$ & $95(92.2)$ & 0.452 & $0.674(0.241-1.887)$ & 0.500 & $0.701(0.249-1.971)$ \\
\hline PPV in DR & $62(86.1)$ & $87(83.7)$ & 0.657 & $1.211(0.520-2.824)$ & 0.501 & $1.347(0.565-3.213)$ \\
\hline Intubation in DR & $60(83.3)$ & $78(75.0)$ & 0.189 & $1.667(0.778-3.572)$ & 0.066 & $2.178(0.948-5.000)$ \\
\hline Surfactant in DR & $33(45.8)$ & $54(52.4)$ & 0.391 & $0.768(0.420-1.404)$ & 0.625 & $0.853(0.450-1.615)$ \\
\hline \multicolumn{7}{|l|}{ NICU course } \\
\hline $\begin{array}{l}\text { Surfactant doses } \\
(\geq 1 \text { dose })\end{array}$ & $65(90.3)$ & $86(82.7)$ & 0.162 & $1.944(0.766-4.929)$ & 0.131 & $2.066(0.806-5.297)$ \\
\hline HFOV use & $46(63.9)$ & $52(50.5)$ & 0.080 & $1.735(0.936-3.215)$ & $0.031 *$ & $2.069(1.068-4.009)$ \\
\hline PPV (>30 days) & $40(55.6)$ & $62(59.6)$ & 0.592 & $0.847(0.461-1.555)$ & 0.710 & $0.890(0.481-1.647)$ \\
\hline $\mathrm{NC}$ (>30 days) & $11(15.3)$ & $17(16.3)$ & 0.849 & $0.923(0.404-2.108)$ & 0.755 & $0.876(0.380-2.019)$ \\
\hline $\begin{array}{l}\text { Mechenical ventilation } \\
\text { (>30 days) }\end{array}$ & $45(62.5)$ & $64(61.5)$ & 0.897 & $1.042(0.561-1.935)$ & 0.549 & $1.227(0.629-2.393)$ \\
\hline Caffeine use & $71(98.6)$ & $101(97.1)$ & 0.522 & $2.109(0.215-20.689)$ & 0.546 & $2.021(0.206-19.881)$ \\
\hline Bacteremia & $24(33.3)$ & $42(40.4)$ & 0.343 & $0.738(0.394-1.382)$ & 0.430 & $0.775(0.411-1.461)$ \\
\hline $\begin{array}{l}\text { Antibiotic days } \\
\text { ( }>30 \text { days) }\end{array}$ & $28(38.9)$ & $47(45.2)$ & 0.412 & $0.999(0.997-1.001)$ & 0.574 & $0.835(0.445-1.566)$ \\
\hline Tracheitis & $26(36.1)$ & $45(43.3)$ & 0.342 & $0.741(0.400-1.375)$ & 0.516 & $0.808(0.425-1.536)$ \\
\hline Pneumonia & $6(8.3)$ & $9(8.7)$ & 0.925 & $0.949(0.322-2.796)$ & 0.936 & $1.047(0.346-3.166)$ \\
\hline
\end{tabular}


Table 3 (continued)

\begin{tabular}{|c|c|c|c|c|c|c|}
\hline Variable & $\begin{array}{l}\text { EPH II }(N=72) \\
n(\%)\end{array}$ & $\begin{array}{l}\text { No EPH II }(N=104) \\
n(\%)\end{array}$ & $P$ value & $\begin{array}{l}\text { Unadjusted OR } \\
(95 \% \mathrm{CI})\end{array}$ & $P$ value & $\begin{array}{l}\text { Adjusted OR } \\
(95 \% \mathrm{CI})\end{array}$ \\
\hline Pneumothorax & $4(5.6)$ & $13(12.5)$ & 0.315 & $0.412(0.129-1.319)$ & 0.154 & $0.427(0.133-1.377)$ \\
\hline IVH $\geq$ Grade III & $20(27.8)$ & $12(11.5)$ & $0.007 *$ & $2.949(1.335-6.513)$ & $0.007 *$ & $3.015(1.358-6.693)$ \\
\hline IVH intervention & $4(5.6)$ & $5(4.8)$ & 0.825 & $1.165(0.302-4.495)$ & 0.865 & $1.124(0.290-4.361)$ \\
\hline PVL & $9(12.5)$ & $7(6.7)$ & 0.197 & $1.980(0.702-5.586)$ & 0.183 & $2.037(0.714-5.808)$ \\
\hline NEC & $20(27.8)$ & $33(31.7)$ & 0.574 & $0.828(0.427-1.602)$ & 0.745 & $0.894(0.454-1.759)$ \\
\hline Intestinal perforation & $15(20.8)$ & $17(16.3)$ & 0.449 & $1.347(0.623-2.910)$ & 0.317 & $1.500(0.678-3.316)$ \\
\hline ROP (any stage) & $48(66.7)$ & $73(70.2)$ & 0.620 & $0.849(0.445-1.620)$ & 0.904 & $0.959(0.485-1.895)$ \\
\hline $\begin{array}{l}\text { Hemodynamically } \\
\text { significant PDA }\end{array}$ & $42(58.3)$ & $57(54.8)$ & 0.643 & $1.154(0.629-2.119)$ & 0.471 & $1.258(0.674-2.350)$ \\
\hline $\begin{array}{l}\text { PDA surgical } \\
\text { closure (any) }\end{array}$ & $15(20.8)$ & $19(18.3)$ & 0.672 & $1.177(0.553-2.506)$ & 0.621 & $1.212(0.565-2.601)$ \\
\hline BPD (severe) & $58(80.6)$ & $78(75.0)$ & 0.388 & $1.381(0.663-2.875)$ & 0.230 & $1.603(0.742-3.463)$ \\
\hline
\end{tabular}

$B P D$ bronchopulmonary dysplasia, $O R$ odds ratio, $C I$ confidence interval, $I U G R$ Intrauterine growth retardation, $P P R O M$ preterm premature rupture of the membranes, $G A$ gestational age, $B W$ birth weight, $S D$ standard deviation, $S G A$ small for gestational age, $C P A P$ continuous positive airway pressure, $P P V$ positive pressure ventilation, $H F O V$ high frequency oscillator ventilator, $N C$ nasal cannula, $I V H$ intraventricular hemorrhage, $P V L$ periventricular leukomalacia, $N E C$ necrotizing enterocolitis, $R O P$ retinopathy of prematurity, $P D A$ patent ductus arteriosus, $E P H$ early pulmonary hypertension, $C$-section cesarean section

Bold values indicate statistical significance $p \leq 0.05$

placement of the tracheostomy tube. This might suggest these infants are at a high risk of having long-term ventilator dependency and so at risk of getting a tracheostomy.

In our cohort, the number of severe BPD patients was slightly higher than many other studies. We attribute this skewness to the severity of illness of patients admitted to the level IV referral based NICU serving most of the underserved population of Philadelphia, PA. Cardiac catheterization has been accepted as the gold standard for diagnosing $\mathrm{PH}$, however it is invasive and is not easily performed in premature neonates, and hence serial echocardiography is recommended as the main tool to screen for PH in BPD patients despite its limitations [46-48]. In our study, the diagnosis of E/LPH was made solely from echocardiography reports read by different pediatric cardiologists, which can cause inter-observer variability. A number of limitations of the BPD definition have been described; however, given its current universal practical value, we chose the NIH consensus definition for our study [49]. Another limitation of our study was that being a retrospective study, we could not control factors such as the consistent timing to get a CE. Despite these limitations, we report some important findings, which could potentially improve the earlier identification and management of premature patients with BPD. The other strengths of our study include the use of standardized definitions and a large sample size of our study cohort. Furthermore, the characteristics of our study population (racial distribution etc.) as well as the management of these infants remained reasonably consistent over the time period at our urban NICU.

\section{Conclusion}

Our study identified novel factors and confirmed some of the previously identified factors for development of BPD-associated LPH and EPH. Based on these results, a risk-based scoring system, which would potentially include pre- and postnatal factors, can be formulated to screen for premature infants at risk for BPD and LPH. We propose to have at least one echocardiogram done to screen for $\mathrm{PH}<$ $28 \mathrm{DOL}$ in premature neonates requiring respiratory support with $\mathrm{FiO}_{2}>0.21$, which can help strategize identification and management of BPD and LPH. Prospective studies are needed to validate this approach.

Acknowledgements The authors are grateful to Alison Carey, MD from St. Christopher's Hospital for Children, Philadelphia, PA for her critical review of the paper.

\section{Compliance with ethical standards}

Conflict of interest The authors declare that they have no conflict of interest.

Publisher's note Springer Nature remains neutral with regard to jurisdictional claims in published maps and institutional affiliations.

\section{References}

1. Berkelhamer SK, Mestan KK, Steinhorn RH. Pulmonary hypertension in bronchopulmonary dysplasia. Semin Perinatol. 2013;37:124-31. 
2. Kim GB. Pulmonary hypertension in infants with bronchopulmonary dysplasia. Korean J Pediatr. 2010;53:688-93.

3. Bhandari V. Drug therapy trials for the prevention of bronchopulmonary dysplasia: current and future targets. Front Pediatr. 2014;2:76.

4. Stoll BJ, Hansen NI, Bell EF, Walsh MC, Carlo WA, Shankaran $\mathrm{S}$, et al. Trends in care practices, morbidity, and mortality of extremely preterm neonates, 1993-2012. JAMA. 2015;314:1039-51.

5. Patel RM, Kandefer S, Walsh MC, Bell EF, Carlo WA, Laptook $\mathrm{AR}$ et al. Causes and timing of death in extremely premature infants from 2000 through 2011. N Engl J Med. 2015;372:331-40.

6. Madurga A, Mižíková I, Ruiz-Camp J, Morty RE. Recent advances in late lung development and the pathogenesis of bronchopulmonary dysplasia. Am J Physiol Lung Cell Mol Physiol. 2013;305:L893-905.

7. De Paepe ME, Mao Q, Powell J, Rubin SE, DeKoninck P, Appel $\mathrm{N}$, et al. Growth of pulmonary microvasculature in ventilated preterm infants. Am J Respir Crit Care Med. 2006;173:204-11.

8. Bhat R, Salas AA, Foster C, Carlo WA, Ambalavanan N. Prospective analysis of pulmonary hypertension in extremely low birth weight infants. Pediatrics. 2012;129:e682-e689.

9. Mourani PM, Sontag MK, Younoszai A, Miller JI, Kinsella JP, Baker $\mathrm{CD}$, et al. Early pulmonary vascular disease in preterm infants at risk for bronchopulmonary dysplasia. Am J Respir Crit Care Med. 2015;191:87-95.

10. Check J, Gotteiner N, Liu X, Su E, Porta N, Steinhorn R, et al. Fetal growth restriction and pulmonary hypertension in premature infants with bronchopulmonary dysplasia. J Perinatol. 2013;33:553.

11. Khemani E, McElhinney DB, Rhein L, Andrade O, Lacro RV, Thomas KC, et al. Pulmonary artery hypertension in formerly premature infants with bronchopulmonary dysplasia: clinical features and outcomes in the surfactant era. Pediatrics. 2007;120:1260-9.

12. An HS, Bae EJ, Kim GB, Kwon BS, Beak JS, Kim EK. et al. Pulmonary hypertension in preterm infants with bronchopulmonary dysplasia. Korean Circ J. 2010;40:131-6.

13. Mirza H, Ziegler J, Ford S, Padbury J, Tucker R, Laptook A. Pulmonary hypertension in preterm infants: prevalence and association with bronchopulmonary dysplasia. J Pediatr 2014;165:909-14.e1.

14. Seo YH, Choi HJ. Clinical utility of echocardiography for early and late pulmonary hypertension in preterm infants: relation with bronchopulmonary dysplasia. J Cardiovasc Ultrasound. 2017;25:124-30.

15. Kaluarachchi DC, Woo KM, Colaizy TT. Role of early pulmonary hypertension as a risk factor for late pulmonary hypertension in extremely preterm infants. Am J Perinatol 2018;35:120-6.

16. Jobe AH, Bancalari E. Bronchopulmonary dysplasia. Am J Respir Crit Care Med. 2001;163:1723-9.

17. Zysman-Colman Z, Tremblay GM, Bandeali S, Landry JS. Bronchopulmonary dysplasia—trends over three decades. Paediatr Child Health. 2013;18:86-90.

18. Poindexter BB, Feng R, Schmidt B, Aschner JL, Ballard RA, Hamvas A, et al. Prematurity and respiratory outcomes program. Comparisons and limitations of current definitions of bronchopulmonary dysplasia for the prematurity and respiratory outcomes program. Ann Am Thorac Soc 2015;12:1822-30.

19. Farrow KN, Steinhorn RH. Pulmonary hypertension in premature infants. Sharpening the tools of detection. Am J Respir Crit Care Med. 2015;191:12-4.

20. Ramos FG, Rosenfeld CR, Roy L, Koch J, Ramaciotti C. Echocardiographic predictors of symptomatic patent ductus arteriosus in extremely-low-birth-weight preterm neonates. J Perinatol. 2010;30:535.

21. Zonnenberg I, de Waal K. The definition of a haemodynamic significant duct in randomized controlled trials: a systematic literature review. Acta Paediatr 2012;101:247-51.

22. Committee on Practice Bulletins-Obstetrics. ACOG Practice Bulletin No. 190: gestational diabetes mellitus. Obstet Gynecol. 2018;131:e49-e64.

23. ACOG Committee on Practice Bulletins-Obstetrics. ACOG practice bulletin. Diagnosis and management of preeclampsia and eclampsia. Number 33, January 2002. Obstet Gynecol. 2002;99:159-67.

24. Committee on Practice Bulletins--Gynecology, American College of Obstetricians and Gynecologists, Washington, DC 20090-6920, USA. Intrauterine growth restriction. Clinical management guidelines for obstetrician-gynecologists. American College of Obstetricians and Gynecologists. Int J Gynaecol Obstet. 2001;72:85-96.

25. ACOG Committee on Practice Bulletins-Obstetrics. ACOG Practice Bulletin No. 80: premature rupture of membranes. Clinical management guidelines for obstetrician-gynecologists. Obstet Gynecol. 2007;109:1007-19.

26. Committee on Obstetric Practice. Committee Opinion No. 712: intrapartum management of intraamniotic infection. Obstet Gynecol. 2017;130:e95-e101.

27. Muszynski JA, Sartori J, Steele L, Frost R, Wang W, Khan N, et al. Multidisciplinary quality improvement initiative to reduce ventilator-associated tracheobronchitis in the PICU. Pediatr Crit Care Med. 2013;14:533-8.

28. Horan TC, Andrus M, Dudeck MA. CDC/NHSN surveillance definition of health care-associated infection and criteria for specific types of infections in the acute care setting. Am J Infect Control. 2008;36:309-32.

29. Doyle LW, Davis PG, Morley CJ, McPhee A, Carlin JB, DART Study Investigators. Outcome at 2 years of age of infants from the DART study: a multicenter, international, randomized, controlled trial of low-dose dexamethasone. Pediatrics. 2007;119:716-21.

30. Papile LA, Burstein J, Burstein R, Koffler H. Incidence and evolution of subependymal and intraventricular hemorrhage: a study of infants with birth weights less than 1,500 gm. J Pediatr. 1978;92:529-34.

31. Banker BQ, Larroche JC. Periventricular leukomalacia of infancy: a form of neonatal anoxic encephalopathy. Arch Neurol. $1962 ; 7: 386-410$.

32. Neu J. Necrotizing enterocolitis: the search for a unifying pathogenic theory leading to prevention. Pediatr Clin North Am. 1996;43:409-32.

33. Gole GA, Ells AL, Katz X, Holmstrom G, Fielder AR, Capone A $\mathrm{Jr}$, et al. The international classification of retinopathy of prematurity revisited. JAMA Ophthalmol. 2005;123:991-9.

34. Nagiub M, Kanaan U, Simon D, Guglani L. Risk factors for development of pulmonary hypertension in infants with bronchopulmonary dysplasia: systematic review and meta-analysis. Paediatr Respir Rev. 2017;23:27-32.

35. Vyas-Read S, Kanaan U, Shankar P, Stremming J, Travers C, Carlton DP, et al. Early characteristics of infants with pulmonary hypertension in a referral neonatal intensive care unit. BMC Pediatr. 2017;17:163.

36. Ali Z, Schmidt P, Dodd J, Jeppesen DL. Predictors of bronchopulmonary dysplasia and pulmonary hypertension in newborn children. Dan Med J. 2013;60:A4688.

37. Slaughter JL, Pakrashi T, Jones DE, South AP, Shah TA. Echocardiographic detection of pulmonary hypertension in extremely low birth weight infants with bronchopulmonary dysplasia 
requiring prolonged positive pressure ventilation. J Perinatol. 2011;31:635.

38. Kumar VH, Hutchison AA, Lakshminrusimha S, Morin FC III, Wynn RJ, Ryan RM. Characteristics of pulmonary hypertension in preterm neonates. J Perinatol. 2007;27:214.

39. Kim DH, Kim HS, Choi CW, Kim EK, Kim BI, Choi JH. Risk factors for pulmonary artery hypertension in preterm infants with moderate or severe bronchopulmonary dysplasia. Neonatology. 2012;101:40-6.

40. Hernández-Díaz S, Van Marter LJ, Werler MM, Louik C, Mitchell AA. Risk factors for persistent pulmonary hypertension of the newborn. Pediatrics. 2007;120:e272-82.

41. McEvoy C, Jain L, Schmidt B, Abman SH, Bancalari E, Aschner J. Bronchopulmonary dysplasia: NHLBI Workshop on the Primary Prevention of Chronic Lung Diseases. Ann Am Thorac Soc. 2014;11 (Suppl 3):S146-53.

42. Manuck TA, Levy PT, Gyamfi-Bannerman C, Jobe AH, Blaisdell CJ. Prenatal and perinatal determinants of lung health and disease in early life: a National Heart, Lung, and Blood Institute Workshop Report. JAMA Pediatr. 2016;170:e154577.
43. Mandell EW, Abman SH. Fetal vascular origins of bronchopulmonary dysplasia. J Pediatr. 2017;185:7-10.

44. Mestan KK, Gotteiner N, Porta N, Grobman W, Su EJ, Ernst LM. Cord blood biomarkers of placental maternal vascular underperfusion predict bronchopulmonary dysplasia-associated pulmonary hypertension. J Pediatr. 2017;185:33-41.

45. Hartge MM, Unger T, Kintscher U. The endothelium and vascular inflammation in diabetes. Diabetes Vasc Dis Res. 2007;4:84-8.

46. Chemla D, Castelain V, Herve P, Lecarpentier Y, Brimioulle S. Haemodynamic evaluation of pulmonary hypertension. Eur Respir J. 2002;20:1314-31.

47. Mourani PM, Mullen M, Abman SH. Pulmonary hypertension in bronchopulmonary dysplasia. Prog Pediatr Cardiol. 2009;27: 43-8.

48. Goodman G, Perkin RM, Anas NG, Sperling DR, Hicks DA, Rowen M. Pulmonary hypertension in infants with bronchopulmonary dysplasia. J Pediatr. 1988;112:67-72.

49. Ibrahim J, Bhandari V. The definition of bronchopulmonary dysplasia: an evolving dilemma. Pediatr Res 2018;84:586-8. 